\title{
Correction to: Gendered impacts of greenhouse gas mitigation options for rice cultivation in India
}

\author{
Hom Gartaula ${ }^{1}$ (D) - Tek B. Sapkota ${ }^{2}$ - Arun Khatri-Chhetri ${ }^{3} \cdot$ Gokul Prasad $^{4}$. \\ Lone Badstue ${ }^{2}$
}

Published online: 28 December 2020

(C) Springer Nature B.V. 2020

\section{Correction to: Climatic Change (2020) 163:1045-1063 https://doi.org/10.1007/s10584-020-02941-w}

The original article has been corrected. The following corrections have been made:

1. Initial was added to second author name: Tek B. Sapkota.

2. Contributors: Hom Gartaula, Tek B Sapkota, and Arun Khatri-Chhetri conceptualized the idea. Hom Gartaula, Tek B Sapkota, Arun Khatri-Chhetri, and Gokul Prasad analyzed data and prepared the manuscript. All authors revised and finalized the manuscript.

3. Funding: This work was funded by the CGIAR Research Programs on Climate Change, Agriculture, and Food Security (CCAFS) and implemented by the International Maize and Wheat Improvement Center (CIMMYT). CCAFS's work is supported by CGIAR Funding Donors and through bilateral funding agreements. For details, please visit https://ccafs.cgiar. org/donors

Publisher's note Springer Nature remains neutral with regard to jurisdictional claims in published maps and institutional affiliations.

The online version of the original article can be found at https://doi.org/10.1007/s10584-020-02941-w

Hom Gartaula

H.GARTAULA@ cgiar.org

1 International Maize and Wheat Improvement Centre (CIMMYT), New Delhi, India

2 International Maize and Wheat Improvement Centre (CIMMYT), El Batan, Mexico

3 International Center of Tropical Agriculture (CIAT), Cali, Colombia

4 Thünen Institute of Climate-Smart Agriculture, Braunschweig, Germany 